\title{
Cell adhesion differentially regulates the nucleocytoplasmic distribution of active MAP kinases
}

\author{
Andrew E. Aplin ${ }^{1,2, *}$, Brian P. Hogan1, Jeannie Tomeu and R. L. Juliano ${ }^{1}$ \\ 1Department of Pharmacology, School of Medicine, University of North Carolina at Chapel Hill, Chapel Hill, NC 27599, USA \\ ${ }^{2}$ Center for Cell Biology and Cancer Research, Albany Medical College, 47 New Scotland Avenue, Albany, NY 12208, USA \\ *Author for correspondence (e-mail: aplina@mail.amc.edu) \\ Accepted 1 April 2002 \\ Journal of Cell Science 115, 2781-2790 (2002) (C) The Company of Biologists Ltd
}

\begin{abstract}
Summary
Cells decide whether to undergo processes, such as proliferation, differentiation and apoptosis, based upon the cues they receive from both circulating factors and integrin-mediated adhesion to the extracellular matrix. Integrins control the activation of the early signaling pathways. For example, growth factor activation of the ERK cascade is enhanced when cells are adherent. In addition, adhesion receptors oversee the cellular localization of critical signaling components. We have recently shown that ERK signaling to the nucleus is regulated by cell adhesion at the level of nucleocytoplasmic trafficking. Since the ERKs are only one class of MAP kinase, we extended these studies to include both JNK and p38 MAP kinases. We have rendered JNK and p38 activation in NIH 3T3 fibroblasts anchorage-independent either by treatment with anisomycin or by expression of
\end{abstract}

upstream activators. Under conditions whereby JNK activation is anchorage-independent, we show that localization of JNK to the nucleus and JNK-mediated phosphorylation of c-Jun and Elk-1 is not altered by loss of adhesion. Likewise, the ability of activated p38 to accumulate in the nucleus was similar in suspended and adherent cells. Finally, we show that expression of a form of ERK, which is activated and resistant to nuclear export, reverses the adhesion-dependency of ERK phosphorylation of Elk-1. Thus, adhesion differentially regulates the nucleocytoplasmic distribution of MAP kinase members; ERK accumulation in the nucleus occurs more efficiently in adherent cells, whereas nuclear accumulation of active p38 and active JNK are unaffected by changes in adhesion.

Key words: Integrins, Nucleus, ERK, JNK, p38, Elk-1

\section{Introduction}

Adhesion to the extracellular matrix (ECM) plays a critical role in the regulation of signaling pathways that ultimately impact on cell proliferation, differentiation and survival. Integrins are the main cellular ECM receptors and connect to the actin cytoskeleton through the formation of specialized sites known as focal contacts and focal adhesions (Calderwood et al., 2000; Hynes, 1992). Thus, cell adhesion initiates dramatic cytoskeletal rearrangements that are important in regulating many signal transduction processes. An important set of pathways regulated by integrins are the MAP kinase cascades. The characteristic feature of MAP kinases is the presence of a common T-X-Y motif within the activation loop: ERKs contain a T-E-Y (Thr-Glu-Tyr) sequence, a T-P-Y (Thr-Pro-Tyr) motif is associated with the c-Jun N-terminal kinases (JNKs), and the p38 subfamily contains a T-G-Y (Thr-Gly-Tyr) sequence (Chang and Karin, 2001; Cobb and Goldsmith, 2000).

The growth factor-mediated activation of ERKs has been shown by several groups to be adhesion-dependent (reviewed by Howe et al., 2002; Schwartz and Baron, 1999). Importantly, additional levels of regulation exist. Upon activation, ERK translocates to the nucleus, where it phosphorylates several transcription factors, such as Elk-1 (Chen et al., 1992; Lenormand et al., 1993; Whitmarsh et al., 1995). We and others have recently shown that the translocation of ERKs from the cytoplasm to the nucleus is also regulated by adhesion (Danilkovitch et al., 2000; Aplin et al., 2001). Furthermore, adhesion enhances ERK-mediated Elk-1 phosphorylation and transactivation potential (Aplin et al., 2001). ERK import into the nucleus is dependent upon both its phosphorylation and homodimerization (Khokhlatchev et al., 1998). The GTPase Ran is important for the transport of a wide variety of molecules in and out of the nucleus (Gorlich and Kutay, 1999). Indeed, Ran is required for import of ERK, although the import factors for ERK that mediate docking to the nuclear pore complex have not been identified (Adachi et al., 1999). Nuclear export of dephosphorylated ERK is mediated by MEK, which has entered the nucleus independently from ERK (reviewed by Cyert, 2001).

Nuclear localization of MAP kinases is vital for fulfillment of many of their activities. Translocation of ERK to the nucleus is required for cell cycle progression and neuronal differentiation (Brunet et al., 1999; Kim et al., 2000; Robinson et al., 1998). JNK and p38 forms of MAP kinases differ from ERK since they are activated more efficiently in response to stress stimuli, such as UV irradiation and inflammatory cytokines, rather than by growth factors (Brunet and Pouyssegur, 1996; Ip and Davis, 1998; Ono and Han, 2000). Subsequently they elicit diverse responses to ERK. Similar to ERK, JNK and p38-mediated phosphorylation of nuclear targets is essential for the initiation of responses downstream of these MAP kinases. Fibroblasts, in which the transcription factor c-Jun has been replaced by a mutant c-Jun deficient in JNK phosphorylation sites, have defects in proliferation and 
response to stress stimuli (Behrens et al., 1999). Additionally, expression of the JNK scaffolding molecule, JNK-interacting protein 1 prevents nuclear translocation of JNK and inhibits growth factor-induced endothelial cell proliferation (Dickens et al., 1997; Pedram et al., 1998).

MAP kinase signaling modules consist of three kinase components that act in sequence. In the classical ERK pathway, Raf phosphorylates MAP/ERK kinases (MEKs) 1 and 2, which in turn phosphorylate ERKs 1 and 2. JNK activation is mediated by the MAP kinase kinases (MKKs) 4 and 7 (Derijard et al., 1995; Lin et al., 1995; Sanchez et al., 1994; Tournier et al., 1997). A variety of activators of MKK4 and MKK7 have been described, including MAP/ERK kinase kinases (MEKKs) 1-4, members of the mixed-lineage kinase family and the apoptosis-stimulated kinases (reviewed by Davis, 2000; Garrington and Johnson, 1999). Activated JNK translocates to the nucleus (Cavigelli et al., 1995; Kawasaki et al., 1996; Mizukami et al., 1997) and is able to phosphorylate a variety of transcription factors, including c-Jun, activating transcription factor 2 (ATF-2), Elk-1 and nuclear factor of activated T cells (NFAT) (Chow et al., 1997; Gille et al., 1995; Price et al., 1996; Whitmarsh et al., 1995). Regulation of p38 isoforms occurs to differing extents through phosphorylation by MKK3, -4 and -6 (Han et al., 1996; Han et al., 1997; Moriguchi et al., 1996; Ono and Han, 2000; Raingeaud et al., 1996; Stein et al., 1996). Activators of MKKs involved in the p38 pathway include MEKK4, apoptosis-stimulated kinases (Ichijo et al., 1997), and transforming growth factor $\beta$ activating kinase (Moriguchi et al., 1996). In the nucleus, p38 phosphorylates Elk-1 and ATF-2, as well as substrates that are not targets for other MAP kinases, such as CHOP/GADD153 (growth arrest and DNA damage inducible gene 153) (Price et al., 1996; Wang and Ron, 1996).

Far less is known about the activation-dependent alterations in the localization of JNK and p38, and the control of their nucleocytoplasmic trafficking, than is known about ERK. JNK localizes to the cytoplasm, the nucleus and, interestingly, focal contacts (Almeida et al., 2000; Dickens et al., 1997; Read et al., 1997). Endogenous p38 in mammalian cells is distributed both in the cytosol and in the nucleus (Raingeaud et al., 1995; Read et al., 1997) and nuclear p38 may be exported upon activation (Ben-Levy et al., 1998). Similarly, in budding and fission yeast the p38 homologs, Hog1 (high osmolarity glycerol response) and Spc1, respectively, are detected both in the cytoplasm and nucleus of unstimulated cells (Ferrigno et al., 1998; Gaits and Russell, 1999). In budding yeast, nuclear accumulation of Hog 1 is impaired in cells with a temperaturesensitive allele of the Ran homolog, Gsp1, when cells were maintained at the restrictive temperature (Ferrigno et al., 1998). Additionally, mutant yeast carrying a deletion of the importin- $\beta$ homlog, NMD5, display impaired nuclear accumulation of Hog1 (Ferrigno et al., 1998). In Schizosaccharomyces pombe, nuclear accumulation of Spc1, in response to osmotic stimuli, requires a functional Pim1, a homologue for the Ran guanine nucleotide exchange factor, RCC1 (Gaits and Russell, 1999). Thus, despite the lack of a consensus nuclear localization sequence in p38, uptake of MAP kinases in yeast appears to be an active process. Nuclear export is mediated by exportins, the best characterized of which is CRM1, which recognizes leucine-rich sequences within the cargo (Gorlich and Kutay, 1999). In fission yeast, the nuclear export of Spc1 is regulated by CRM1 (Gaits and Russell, 1999).

Since regulation of MAP kinase accumulation in the nucleus has important biological ramifications, we analyzed whether the adhesion regulation of nucleocytoplasmic trafficking observed for ERK extended to other MAP kinases, namely JNK and p38. We show that activation of both JNK and p38 can be rendered anchorage-independent either by treatment with anisomycin or, in the case of JNK, by expression of active MEKK1. We find that active JNK and active p38 accumulate in the nucleus both in suspended and adherent cells. Furthermore, activated JNK efficiently phosphorylates the transcription factors, c-Jun and Elk-1, regardless of anchorage. In contrast, ERK-mediated phosphorylation is anchoragedependent (Aplin et al., 2001), a level of control that is bypassed by expression of an active form of ERK that accumulates in the nucleus.

\section{Materials and Methods}

\section{Plasmids}

The FLAG epitope-tagged Elk-1 in pCMV5 (Yang et al., 1998) was generously provided by Andrew Sharrocks (School of Biological Sciences, University of Manchester, UK). Use of pCDNA3-22W Raf has been previously described (Aplin et al., 2001). pCMV5$\triangle \mathrm{MEKK} 1$, encoding an $\mathrm{N}$-terminally truncated activated version of MEKK1 was from Gary Johnson (University of Colorado Health Sciences Center, Denver, CO) (Fanger et al., 1997). pCMV5-ERK2MEK1-LA encoding an ERK-MEK fusion protein that has the leucine-based nuclear export signal in MEK rendered inactive by mutation to alanine residues was donated by Melanie Cobb (Southwestern Medical Center, University of Texas) (Robinson et al., 1998).

\section{Antibodies}

Antibodies to phospho(Ser63) c-Jun, phospho(Ser73) c-Jun, phospho(Thr183/Tyr185) JNK, phospho(Thr180/Tyr182) p38, phospho(Thr202/Tyr204) ERK and phospho(Ser383) Elk-1 were purchased from Cell Signaling Technology (Beverly, MA). Other antibodies used in this study were anti-c-Jun (Transduction labs., Lexington KY); anti-Elk-1 clone I-20, anti-JNK clone C-17, anti-Raf clone C-12, anti-p38 clone N-20, and anti-MEK1 clone C-22 (from Santa Cruz Biotechnology, CA); anti-FLAG M2 (from Sigma); and anti-HA clone, 12CA5 and anti-Myc clone 9E10 (from BabCo, Richmond, CA).

\section{Cell culture and transfection}

NIH3T3 cells were maintained in Dulbecco's minimal essential medium (DMEM) containing 10\% bovine calf serum and transfected with SuperFect (Qiagen, Valencia, CA) according to the manufacturer's instructions.

\section{Cell adhesion and preparation of cell lysate}

Serum-starved cells were detached with trypsin/EDTA. Trypsin activity was quenched with DMEM/BSA containing $1 \mathrm{mg} / \mathrm{ml}$ soybean trypsin inhibitor. Cells were washed and rolled for 45 minutes on a rotating platform in DMEM/BSA. At this time, cells were either maintained in suspension or replated onto dishes coated with $10 \mu \mathrm{g} / \mathrm{ml}$ fibronectin (BD Biosciences, Bedford, MA) for a further 2 hours. Cells were stimulated appropriately with anisomycin (Calbiochem) before lysis in modified RIPA buffer containing $50 \mathrm{mM}$ Hepes, $\mathrm{pH} 7.5,1 \%$ NP-40, $0.5 \%$ sodium deoxycholate, $150 \mathrm{mM} \mathrm{NaCl}, 50 \mathrm{mM} \mathrm{NaF}, 1 \mathrm{mM}$ 
sodium vanadate, $1 \mathrm{mM}$ nitrophenylphosphate, $0.2 \mu \mathrm{M}$ calyculin $\mathrm{A}, 1$ $\mathrm{mM}$ AEBSF and $10 \mu \mathrm{g} / \mathrm{ml}$ aprotinin (Aplin and Juliano, 1999).

\section{Immunoprecipitation and western blotting}

For immunoprecipitations, cell lysates were first precleared by incubating for 30 minutes at $4^{\circ} \mathrm{C}$ with protein G-sepharose. FLAGElk-1 was immunopreciptiated from precleared lysates with antiFLAG antibody overnight at $4^{\circ} \mathrm{C}$, followed by the addition of protein G-Sepharose and then further incubated for 2 hours at $4^{\circ} \mathrm{C}$. Precipitates were washed three times with cold RIPA buffer and boiled with SDS-PAGE sample buffer to dissociate the proteins.

For analysis by western blotting, samples were separated by SDSPAGE under reducing conditions. Immunoreactivity was detected using horse-radish peroxidase-conjugated secondary antibodies and enhanced chemiluminescence (Amersham, Arlington Heights, IL), as previously described (Lin et al., 1997).

\section{In vitro kinase assays}

Protein $\mathrm{G}$ pellets from immunoprecipitations were washed once in modified RIPA buffer and twice in high salt buffer (Lin et al., 1997). Pellets were then re-suspended in $40 \mu \mathrm{l}$ of kinase assay buffer containing $10 \mathrm{mM}$ Tris, pH 7.5, $10 \mathrm{mM} \mathrm{MgCl} 2,1 \mathrm{mM}$ DTT, $10 \mu \mathrm{M}$ ATP, $5 \mu \mathrm{Ci}\left[\gamma_{-}{ }^{32} \mathrm{P}\right]$-ATP (370 MBq/ml; Du Pont, Boston, MA) and 2 $\mu \mathrm{g}$ of recombinant GST-cJun (1-133), and incubated for 30 minutes at room temperature. Reactions were terminated by the addition of 13 $\mu \mathrm{l}$ of $4 \times$ sample buffer and boiling for 5 minutes. The samples were subjected to SDS-PAGE, and the gels were dried. The dried gels were exposed to X-ray films, and the [ $\left.{ }^{32} \mathrm{P}\right]$-labeled substrate bands were

\section{A}
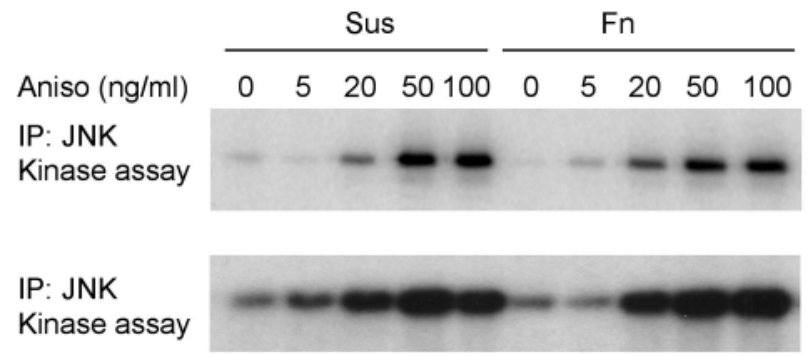

$30 \mathrm{~min}$

B

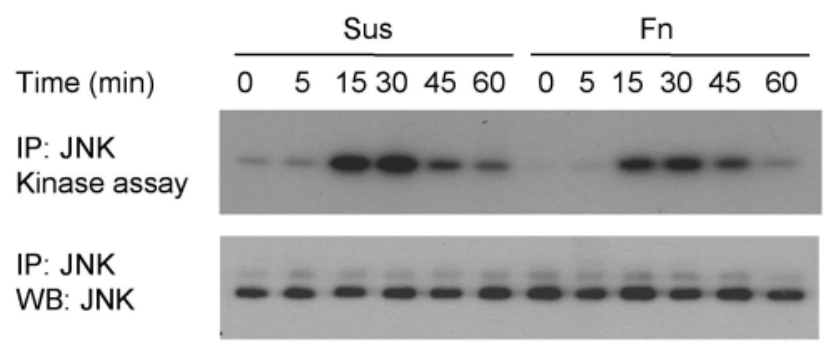

Fig. 1. Anisomycin treatment activates JNK regardless of the state of anchorage. Serum-starved detached NIH 3T3 cells were either maintained in suspension (Sus) or plated onto fibronectin (Fn)-coated dishes for 2 hours in DMEM/BSA. (A) Cells at the 2 hour time point were stimulated appropriately with increasing doses of anisomycin $(0,5,20,50$ and 100 $\mathrm{ng} / \mathrm{ml}$ ) for either 15 minutes or 30 minutes, as indicated. (B) Cells were stimulated with $50 \mathrm{ng} / \mathrm{ml}$ anisomycin for $0,5,15,30,45$ and 60 minutes, as indicated. Under each condition, cells were lysed in modified RIPA buffer and endogenous JNK activity determined by immunoprecipitation with C-17 and in vitro kinase assay using GST-c-Jun as the substrate. Incorporation of ${ }^{32} \mathrm{P}$ into GST-c-Jun was determined by autoradiography. quantified using a Storm 840 PhosphorImager with Image-QuaNT software (Molecular Dynamics, Sunnyvale, CA).

\section{Immunofluorescence microscopy}

Cells replated on glass coverslips, pre-coated with fibronectin or polylysine (Sigma), were fixed in 3.7\% formaldehyde in Dulbecco's phosphate buffered saline (PBS) for 10 minutes, rinsed in PBS, and permeabilized for 5 minutes in PBS containing $0.5 \%$ Triton X-100 prior to staining. Nonspecific staining was blocked with $2 \%$ BSA/PBS and all subsequent antibody reactions were performed in $2 \%$ BSA/PBS. Slides were incubated with the indicated primary antibody overnight at $4^{\circ} \mathrm{C}$. Coverslips were rinsed extensively in PBS and then stained with either FITC-conjugated goat anti-mouse, FITCconjugated swine anti-rabbit or TRITC-conjugated goat anti-rabbit IgG for 60 minutes at ambient temperature, as appropriate. Phospho JNK and phospho p38 were detected with AlexaFluor 488 anti-rabbit IgG (Molecular Probes, Eugene, OR). Following the antibody incubations, the coverslips were washed in PBS, rinsed in deionized water, and mounted in Permafluor (Thomas, Swedesboro, NJ). Nuclei were stained with Hoechst 33342 reagent (Molecular Probes). Slides were viewed either on a Zeiss Axioskop or an Olympus BX60 microscope equipped for epifluorescence and with image capturing software.

\section{Results}

Anisomycin activates the JNK pathway in an anchorageindependent manner

Studies with HUVECs have demonstrated that JNK activation, in response to tumor necrosis factor $\alpha$, is adhesiondependent, although the actual point of convergence in the pathway remains to be determined (Short et al., 1998). In order to examine the effect of adhesion upon the ability of activated JNK to accumulate in the nucleus and phosphorylate nuclear targets, we initially sought to set up conditions whereby JNK was activated in an anchorageindependent manner. To this end, we treated NIH 3T3 mouse fibroblasts that were either adherent to fibronectin or maintained in suspension, with increasing doses of anisomycin. The bacterial compound anisomycin potently activates the MEKK/MKK/JNK pathway at the level of, or above, MEKK (Kawasaki et al., 1996; Meier et al., 1996). In vitro kinase assays using recombinant GST-c-Jun as the substrate showed that anisomycin efficiently activated the JNK pathway at concentrations equal to or above $20 \mathrm{ng} / \mathrm{ml}$, irrespective of the state of anchorage (Fig. 1A). Under both adherent and suspension conditions, JNK activation followed a similar time course. Activation of JNK occurred by 15 minutes and was persistent through 30 minutes, but decreased thereafter (Fig. 1B). Thus, anisomycin treatment is able to render JNK activation anchorage-independent.

\section{Active JNK accumulates in the nucleus and efficiently phosphorylates the nuclear transcription factor c-Jun in suspended cells}

Once activated, JNK accumulates in the nucleus and phosphorylates several transcription factors. c-Jun is selectively phosphorylated at serines 63 and 73 and transcriptionally activated by JNK, but not ERK (Minden et al., 1994). We tested whether or not adhesion affected 


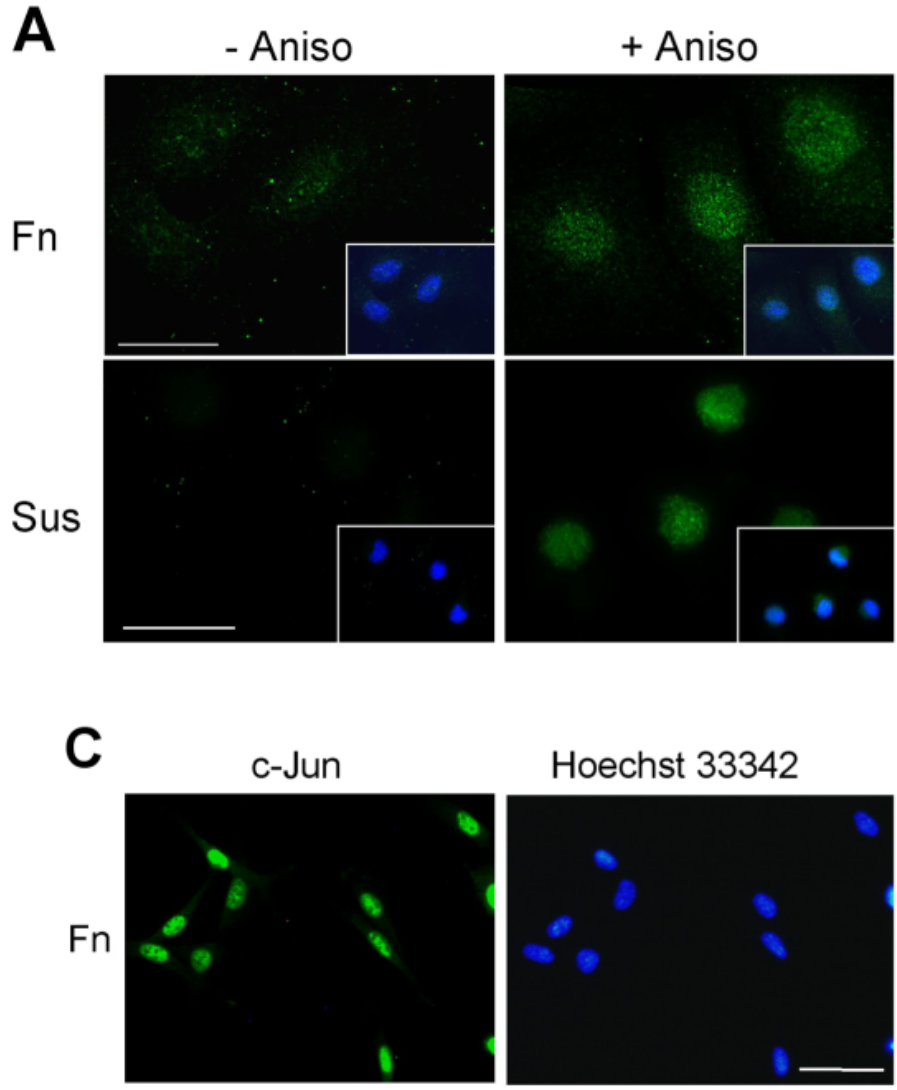

Fig. 2. Activated JNK phosphorylates the nuclear transcription factor c-Jun regardless of adhesion. Serum-starved detached NIH 3T3 cells were either plated onto fibronectin (Fn)-coated coverslips or maintained in suspension (Sus) for 2 hours in DMEM/BSA. At this time, cells were stimulated appropriately with anisomycin $(50 \mathrm{ng} / \mathrm{ml})$ for 30 minutes. Suspended cells were plated on poly-lysine-coated coverslips for the final 15 minutes. Cells were washed briefly in PBS before fixation. Cells were processed by immunofluorescence for phospho-JNK (A), phosphoserine-63 c-Jun (B), and total c-Jun (B,C). Primary antibody staining was detected with the appropriate fluorophore-conjugated anti-rabbit and anti-mouse IgG. In A, inserts show the overlay between phospho-JNK and nuclear staining with Hoechst 33342 reagent. Bars, $20 \mu \mathrm{M}(\mathrm{A}) ; 50 \mu \mathrm{M}(\mathrm{B}, \mathrm{C})$.

the ability of anisomycin-activated JNK to accumulate in the nucleus and phosphorylate c-Jun. Treatment with $50 \mathrm{ng} / \mathrm{ml}$ anisomycin enhanced anti-phospho JNK staining by immunofluorescence in both adherent and suspended cells compared with non-treated controls (Fig. 2A). In both adherent and suspended cells, the majority of phospho-JNK localized to the nucleus. Furthermore, we visualized the phosphorylation of c-Jun using phosphorylation-state-specific antibodies. c-Jun was poorly phosphorylated at Ser63, when cells were either adherent to fibronectin or maintained in suspension for 3 hours in the absence of an added stimulus (Fig. 2B). Under both adherent and suspended conditions, robust phosphorylation was observed in response to anisomycin-mediated activation of the JNK pathway (Fig. 2B). Similarly, phosphorylation of cJun at Ser73, in response to anisomycin treatment, was detectable under both suspension and adherent conditions (data not shown). Endogenous c-Jun in NIH 3T3 cells was exclusively localized to the nucleus (Fig. 2C).

We next examined the extent of c-Jun phosphorylation over the range of doses that anisomycin-induced activation of JNK.
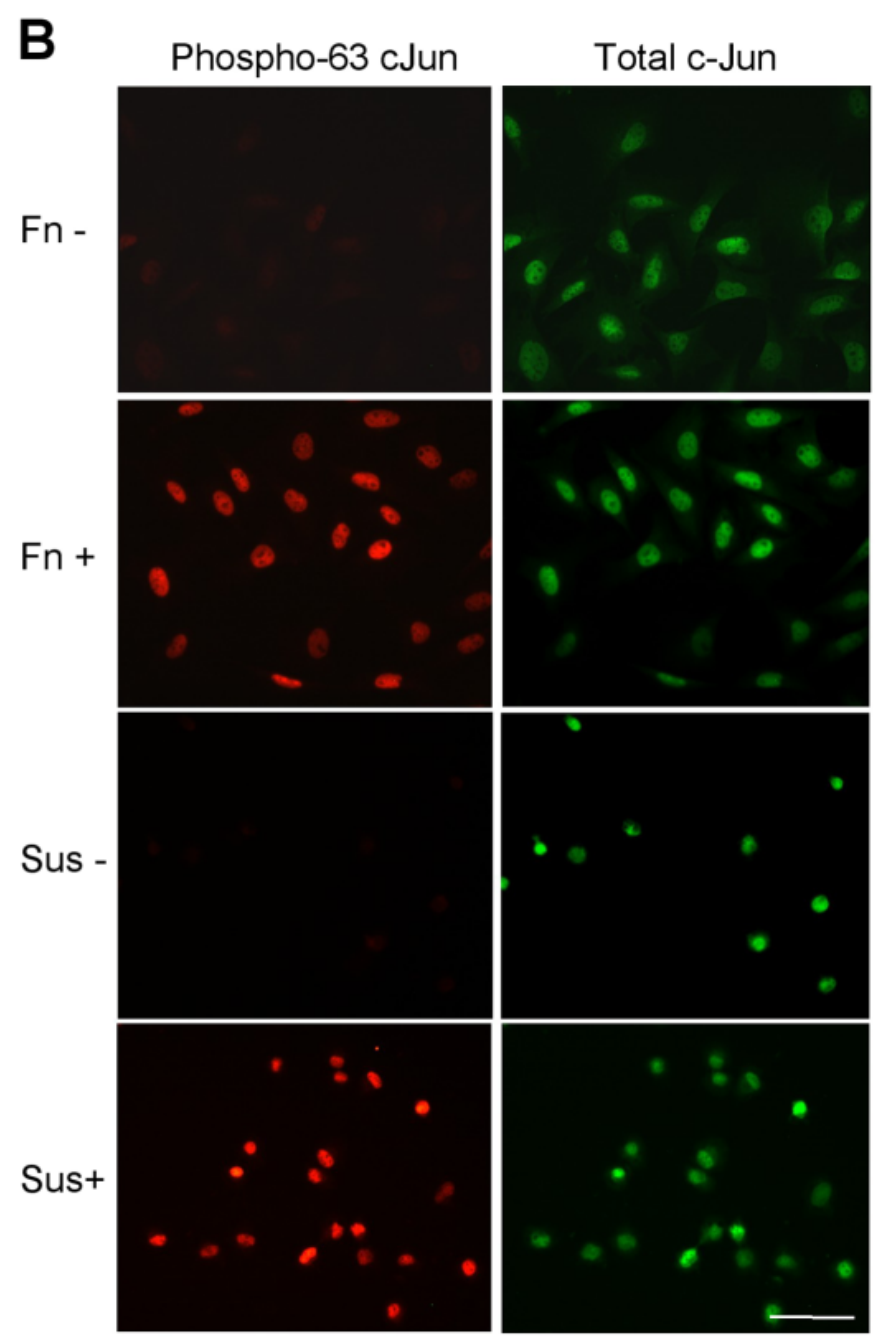

Cells were either maintained in suspension or allowed to adhere to fibronectin, before stimulation with increasing doses of anisomycin. Phosphorylation of c-Jun at Ser63 and Ser73 was determined by western blotting. Consistent with observations in the immunofluorescence experiments, c-Jun phosphorylation was low in unstimulated cells (Fig. 3A). Robust phosphorylation of c-Jun at both Ser63 and Ser73 was induced in response to treatment with a $20 \mathrm{ng} / \mathrm{ml}$ or higher dose of anisomycin. The level of c-Jun phosphorylation was comparable at equivalent anisomycin concentrations both in suspended and adherent cells (Fig. 3A). The level of total cJun was unaltered by the state of adhesion and a mobility shift, characteristic of enhanced phosphorylation, was observed at high anisomycin doses (Fig. 3A, lower panel). Additionally, the time course of c-Jun phosphorylation, at both Ser63 and Ser73, was equivalent regardless of the state of adhesion (Fig. $3 \mathrm{~B})$. The combination of immunofluorescence and biochemical approaches demonstrates that activated JNK is able to localize efficiently to the nucleus and phosphorylate a nuclear target in an anchorage-independent manner. 


\section{A}

\begin{tabular}{|c|c|c|c|c|c|}
\hline \multirow[b]{2}{*}{ Anisomycin (ng/ml) } & \multicolumn{3}{|r|}{ Sus } & \multicolumn{2}{|r|}{$\mathrm{Fn}$} \\
\hline & 0 & 5 & 2050100 & 05 & $20 \quad 50100$ \\
\hline
\end{tabular}

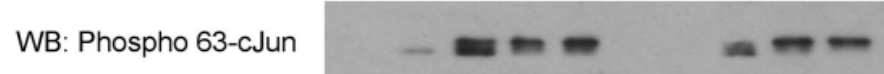

WB: Phospho 73-cJun

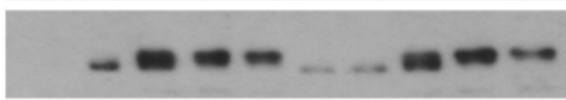

WB: Total cJun

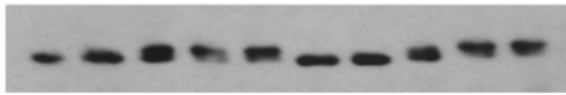

B

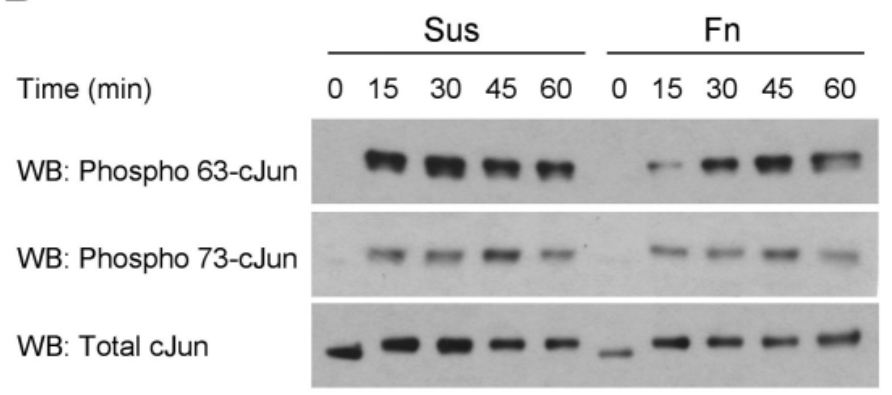

Fig. 3. Phosphorylation of c-Jun by activated JNK is adhesion independent over a range of anisomycin concentrations. Serum-starved detached NIH 3T3 cells were either plated onto fibronectin (Fn)coated dishes or maintained in suspension (Sus) for 2 hours in DMEM/BSA. At this time point, cells were stimulated (A) with increasing doses of anisomycin $(0,5,20,50$ and $100 \mathrm{ng} / \mathrm{ml})$ for 30 minutes or (B) with $50 \mathrm{ng} / \mathrm{ml}$ anisomycin for the times indicated. Under each condition, cells were lysed in modified RIPA buffer and lysates analyzed by western blotting for phosphoserine-63 c-Jun (Phospho63-cJun), phosphoserine-73 c-Jun (Phospho73-cJun) and total c-Jun. The results shown are representative of three independent experiments.

Adhesion to fibronectin is required for active ERK, but not active JNK-mediated phosphorylation of Elk-1

The lack of anchorage control of JNK-mediated c-Jun phosphorylation contrasted with our previous findings in the ERK pathway that demonstrated that even when ERK is activated, adhesion signals are required for ERK to accumulate in the nucleus and phosphorylate Elk-1 (Aplin et al., 2001). Thus, we employed the expression constructs, $22 \mathrm{~W}$ Raf and $\triangle \mathrm{MEKK} 1$, which are active versions of components of the ERK and JNK pathway, respectively. Overexpressed active MEKK1 was predominately localized in the cytoplasm and was excluded from the nucleus with the exception of staining in the nucleolus (Fig. 4A). 22W Raf also showed predominantly a cytoplasmic localization (Fig. 4A). We used a FLAG-tagged version of the transcription factor, Elk-1, as a common substrate of ERK and JNK (Gille et al., 1995; Janknecht et al., 1993; Price et al., 1996; Whitmarsh et al., 1995; Yang et al., 1998). The overexpressed FLAG-Elk1 localized to the nucleus in both adherent and suspended cells (Fig. 4B). We have previously shown $22 \mathrm{~W}$ Raf-mediates equivalent activation of ERK in suspended and adherent cells (Aplin et al., 2001). Despite anchorage-independent ERK activation, Elk-1 phosphorylation is anchorage-dependent in cells transfected with 22W Raf (Fig. 4C, lanes 3,4). However, when an activated form of MEKK1 was expressed, Elk-1 phosphorylation at Ser383 was anchorage-independent (Fig. 4C, lanes 5,6). Thus, the ability of activated JNK to phosphorylate nuclear transcription factors is not regulated by adhesion to the ECM, in contrast to activated ERK, which requires adhesion to efficiently phosphorylate Elk-1.

\section{Anisomycin activates the p38 pathway in an anchorage-} independent manner

We also examined activation of the p38 pathway under adhesion and suspension conditions. Anisomycin potently activates the p38 MAP kinase cascade at, or upstream of, MKK6 (Hazzalin et al., 1996). We tested whether anisomycin activated p38 in an anchorage-independent manner. Initially, we stimulated cells that were either in suspension or readhered to fibronectin with different doses of anisomycin for 30 minutes. We probed for p38 activation using a phosphospecific antibody that detects dually phosphorylated (threonine 180 and tyrosine 182) forms of p38. Anisomycintreatment resulted in phosphorylation of $\mathrm{p} 38$, in both suspended and adherent cells, over a similar concentration range used for the JNK experiments (Fig. 5A). Phosphorylation of p38 occurred within 15 minutes and was persistent through the 60 minute time-point (Fig. 5B). Thus, similar to the JNK pathway, anisomycin treatment of NIH 3T3 cells activates the p38 pathway, irrespective of the state of anchorage.

\section{Active p38 accumulates in the nucleus of non-adherent and adherent cells}

We next examined the effects of adhesion on the accumulation of active p38 in the nucleus upon anisomycin-treatment. NIH 3T3 cells were placed in suspension or re-adhered to fibronectin and treated with anisomycin for 30 minutes, and the localization of phospho-p38 analyzed by immunofluorescence. Treatment of cells with anisomycin resulted in increased phospho-p38 staining in both adherent and suspended cells (Fig. 6). In both states of adhesion, active p38 accumulated in the nucleus. Since both Elk-1 and ATF-2 are phosphorylated by both JNK and p38, we were unable to examine direct phosphorylation of these transcription factors as a read-out of nuclear p38 activity in response to anisomycin treatment. However, expression of an active form of a p38 upstream activator, MKK3, initiated phosphorylation of Elk-1 in both suspended and adherent cells (data not shown). Together, these data indicate that, similar to our findings with JNK, the nucleocytoplasmic distribution of activated p38 is unaffected by changes in cellular adhesion.

\section{Expression of active nuclear-targeted form of ERK recovers Elk-1 phosphorylation in suspended cells}

Our findings highlight differences between adhesion regulation of MAP kinases, notably in their localization and ability to signal to nuclear transcription factors. In these and previous studies [Fig. 4C (Aplin et al., 2001)], we have shown that ERK 
A
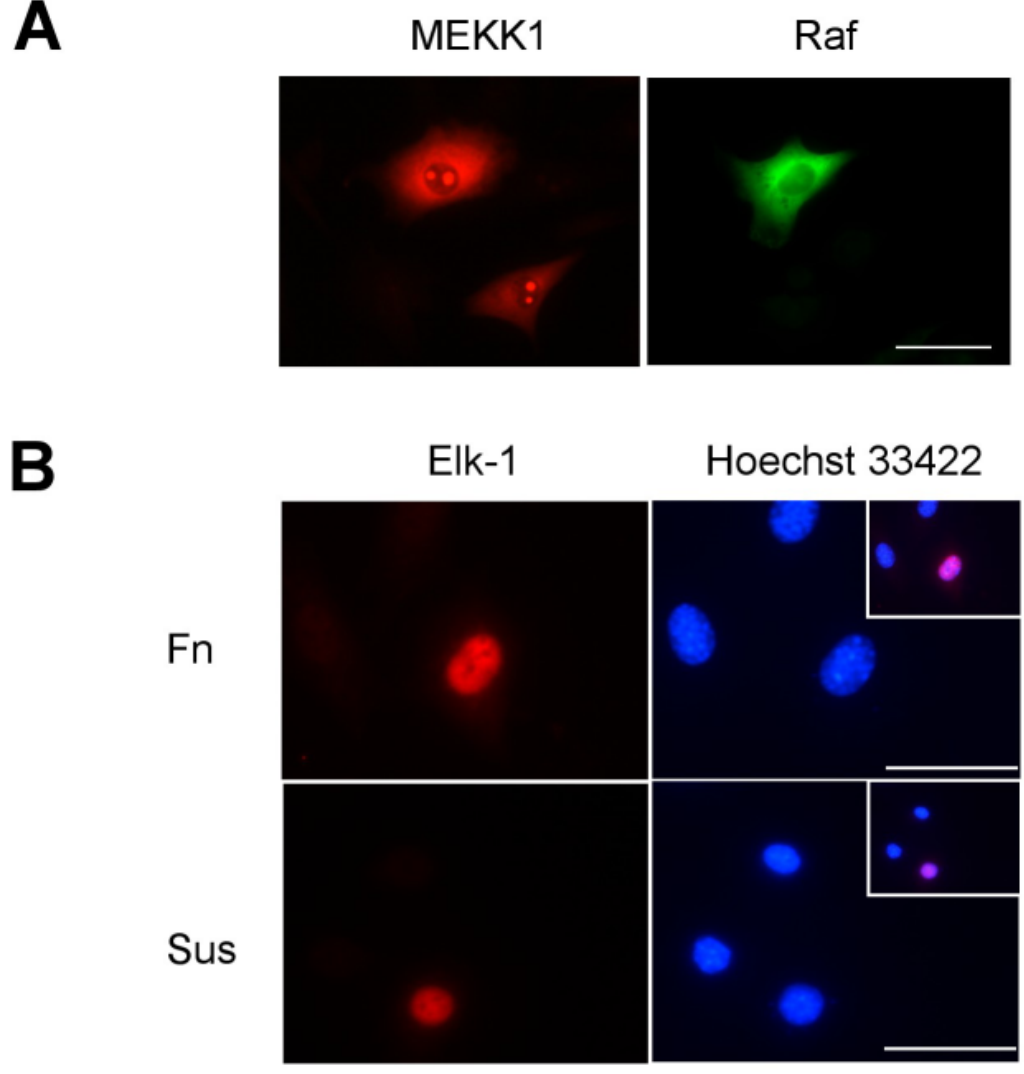

C

IP: FLAG

WB: P-383-Elk-1

IP: FLAG

WB: Elk-1
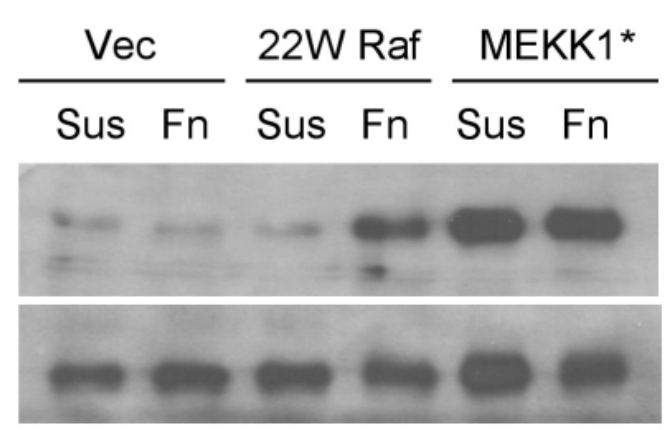

Fig. 4. Phosphorylation of Elk-1 is anchorage-dependent upon activation of the ERK pathway, but anchorageindependent upon activation of the JNK pathway. (A) NIH 3 T3 cells were transfected with either $\triangle$ MEKK1 or $22 \mathrm{~W}$ Raf. Cells were replated onto fibronectin-coated coverslips. The localization of MEKK1 and Raf were determined by immunofluorescence using either TRITC or FITC-conjugated anti-rabbit secondary antibodies. Bar, $25 \mu \mathrm{M}$. (B) Cells expressing FLAG-Elk-1 were plated onto Fn-coated dishes or maintained in suspension (Sus) and analyzed by immunofluorescence with antiElk-1 antibodies. Insets show the overlay of Elk-1 and nuclear staining. (C) Cells were transfected with FLAGElk-1 and either vector 22W Raf or $\triangle \mathrm{MEKK} 1$. After 24 hours, transfected cells were serum-starved before being replated in DMEM/BSA onto Fn-coated dishes or maintained in suspension (Sus) for a further 3 hours. Ectopically expressed Elk-1 was immunoprecipitated from cell lysates from each condition with an M2 FLAG epitope antibody. FLAG-Elk-1 immunoprecipitates were analyzed by western blotting for levels of Ser383-

phosphorylated and total Elk-1. The results shown are representative of at least three independent experiments with equivalent results.

phosphorylation of Elk-1; control that is by-passed by targeting nuclear accumulation of ERK.

\section{Discussion}

Compartmentalization of signaling molecules is an important regulatory mechanism that enables the cell to build up an elaborate network of signaling pathways. Cell adhesion molecules, such as integrins, regulate the localization of a variety of signaling molecules. Del Pozo and colleagues have shown that the recruitment of GTP-loaded Rac to membranous sites is enhanced in adherent cells (del Pozo et al., 2000). Conversely, loss of adhesion in mammary epithelial cells leads to a rapid movement of the pro-apoptotic protein, Bax, to the mitochondria (Gilmore et al., 2000). We and others have previously shown that nucleocytoplasmic trafficking of kinases, such as ERK and c-Abl, is also regulated by adhesion (Aplin et al., 2001; activated by $22 \mathrm{~W}$ Raf poorly signals to the nucleus in suspended cells. Next, we decided to determine whether enhancing nuclear-targeting of ERK could recover phosphorylation of Elk-1. To this end, we expressed a construct (ERK2-MEK1-LA) encoding an ERK-MEK fusion protein that has the leucine-based nuclear export signal in MEK rendered inactive by mutation to alanine residues. In cells, ERK2-MEK1-LA accumulates in the nucleus and is constitutively active (Robinson et al., 1998). When expressed in NIH 3 T3 cells, western blot and in vitro kinase analyses determined that the phosphorylation and kinase activity of ERK2-MEK1-LA were anchorage-independent (Fig. 7A). As before, expression of active Raf resulted in efficient phosphorylation of Elk-1 in adherent but not suspended cells. By contrast, Elk-1 phosphorylation at Ser383 in NIH 3T3 cells expressing the ERK2-MEK1-LA construct was anchorageindependent (Fig. 7B). These data indicate that adhesion regulation of ERK localization is critical for efficient
Danilkovitch et al., 2000; Lewis et al., 1996; Woodring et al., 2001). Control of trafficking between the nuclear and cytoplasmic compartments is critical for gene expression in response to a variety of stimuli and therefore provides an important mechanism whereby cell adhesion molecules may regulate biological events.

Here, we have expanded our studies on adhesion regulation of MAP kinase compartmentalization to the JNK and p38 subfamilies. We find that in contrast to the ERK pathway, in which accumulation in the nucleus is impaired in non-adherent cells, activated JNK and p38 are able to efficiently localize and, in the case of JNK, impact on nuclear events in the absence of integrin-mediated engagement. Studies on the JNK pathway were of particular interest since recent reports have demonstrated the presence of phosphorylated forms of JNK both in focal adhesions and in the nucleus upon adhesion to fibronectin (Almeida et al., 2000). However, our observations argue against the possibility of adhesion-dependent trafficking 
of JNK between focal adhesion sites and the nucleus. Several reports have demonstrated that JNK is directly activated by integrin-mediated adhesion in the absence of additional signals (MacKenna et al., 1998; Mainiero et al., 1997; Miyamoto et al., 1995; Oktay et al., 1999). In our studies, it is important to emphasize that we examined changes in nuclear activity in response to activation in pre-adherent cells, as opposed to JNK activation directly in response to adhesion. Whether differences exist in the ability of JNK to localize to the nucleus, when activated by adhesion versus anisomycin treatment, remains to be determined.

Studies in COS cells show that over-expressed p38 is detected both in the cytoplasm and the nucleus under basal conditions (Raingeaud et al., 1995). In contrast, p38 in 293T cells is primarily localized to the nucleus, a proposed site of activation (Ben-Levy et al., 1998). In 293T cells, activation of p38 results in the phosphorylation of MAPKAP kinase-2, which then promotes nuclear export of active p38 via a leptomycin-B dependent mechanism (Ben-Levy et al., 1998; Engel et al., 1998). In NIH 3 T3 cells, we clearly observed phosphorylated p38 co-localization with staining for the nucleus, although it remains unresolved in our cell system whether activation of p38 occurs in the cytoplasm or in the nucleus.

Finally, we have extended our studies on the ERK cascade. We have previously shown that activation of ERK by expression of active versions of upstream components in the pathway, namely Raf and MEK, renders ERK activation anchorageindependent. However, subsequent accumulation of ERK within the nucleus and phosphorylation of Elk-1 are anchoragedependent (Aplin et al., 2001). The mechanism whereby adhesion regulates ERK nucleocytoplasmic trafficking remains to be determined. At the level of ERK, adhesion may regulate the release from cytoplasmic anchoring proteins, the rate of import and/or the rate of export (Cyert, 2001). Here, we have used an ERKMEK fusion, which is active and accumulates in the nucleus due to mutation of the nuclear export sequence in MEK (Robinson et al., 1998). Our findings with ERK-MEK-LA add to our understanding of adhesion regulation of ERK. Notably, ERK-MEK-LA is phosphorylated within the activation loop and is active in suspended cells (Fig. 7A) indicating that the activities of MKPs that downregulate ERK are not dramatically increased in suspended cells. Additionally, expression of ERK-MEK-LA leads to Elk-1 phosphorylation in suspended cells arguing against the possibility that increased Elk-1 phosphatase activity underlies the decreased Elk-1 phosphorylation in our 22W Raf experiments. Our findings with ERK-MEKLA do not distinguish between altered import and export because these processes may be affected by the overexpression of ERK-MEK-LA, and the comparable wild-type version of ERK-MEK does not possess a suitable specific activity (Robinson et al., 1998). Future experiments involving temporal regulation of activated endogenous ERK should shed light on this issue. However, these findings underscore the importance of adhesion regulation of ERK trafficking between the cytoplasm and the nucleus for effects on nuclear transcription factors and possibly for adhesiondependent cell cycle events.

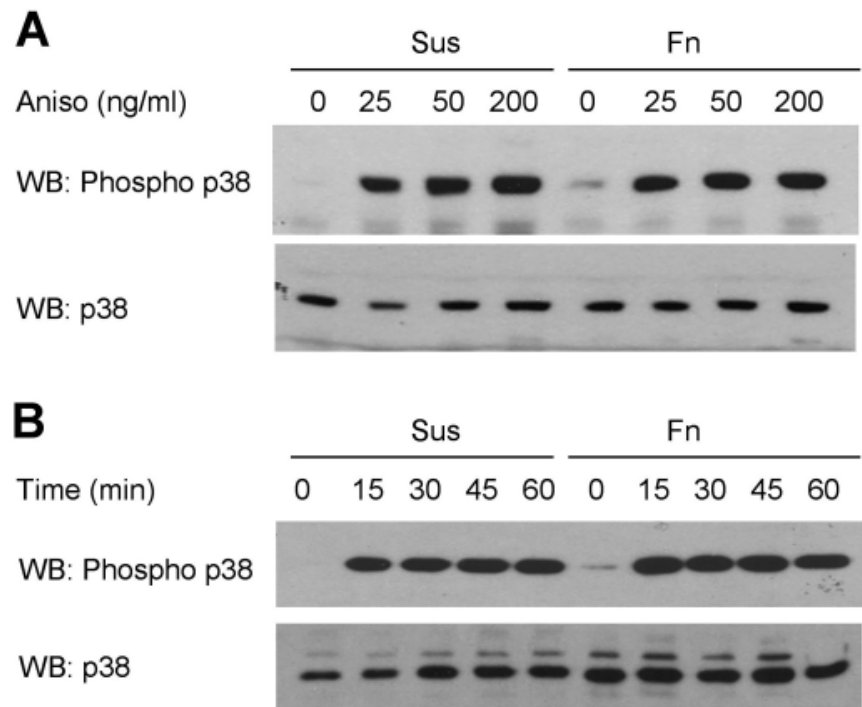

Fig. 5. Anisomycin treatment activates p38 in an anchorageindependent manner. Serum-starved detached NIH 3T3 cells were either maintained in suspension (Sus) or plated onto fibronectin (Fn)-coated dishes for 2 hours in DMEM/BSA. (A) At the 2 hour time point, cells were stimulated appropriately with increasing doses of anisomycin $(0,25,50$ and $200 \mathrm{ng} / \mathrm{ml})$ for the 30 minutes.

(B) Cells were treated with $50 \mathrm{ng} / \mathrm{ml}$ anisomycin for the times indicated. Under each condition, cells were lysed in modified RIPA buffer and cell lysates probed with antibodies to phosphorylated and total p38.

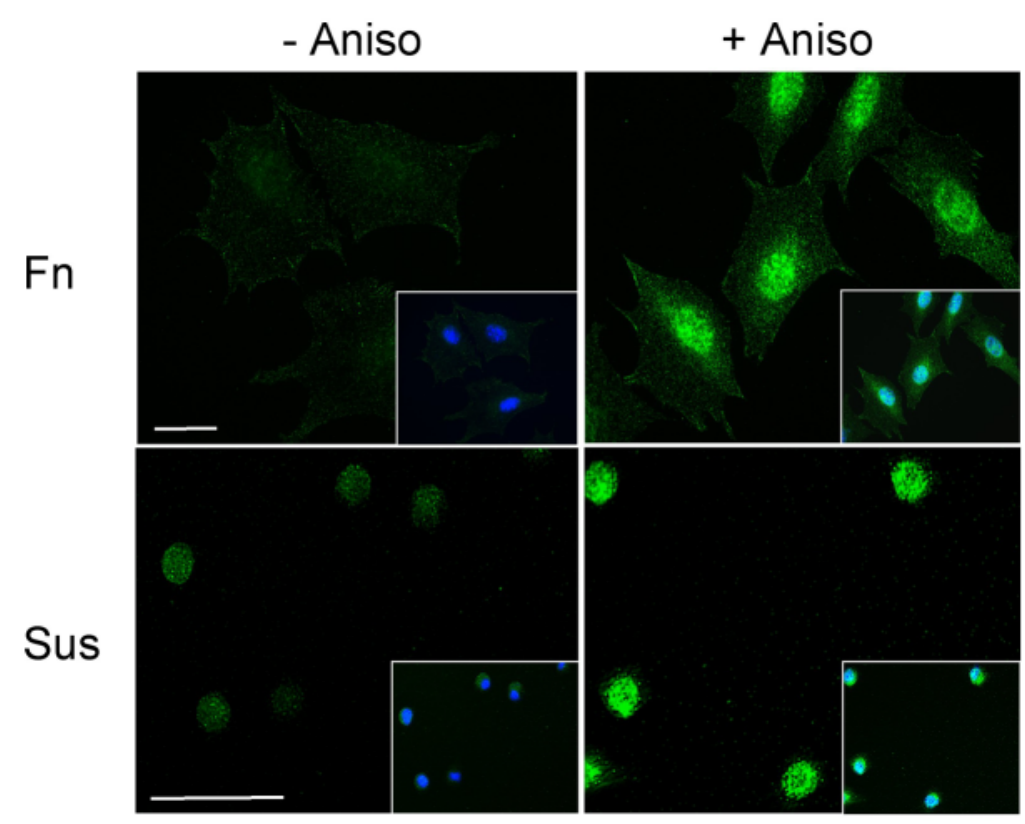

Fig. 6. Phosphorylated p38 accumulates in the nucleus in both adherent and non-adherent cells. Serum-starved detached NIH 3T3 cells were either plated onto fibronectin (Fn)-coated dishes or maintained in suspension (Sus) for 2 hours in DMEM/BSA before being stimulated with $50 \mathrm{ng} / \mathrm{ml}$ anisomycin for 30 minutes. Suspended cells were allowed to adhere to poly-lysine-coated coverslips for the final 15 minutes. Fixed cells were analyzed by immunofluorescence for phospho-p38. Bars, $20 \mu \mathrm{M}$. Inserts show the overlay between phospho-p38 and nuclear staining with Hoechst 33342 reagent. 


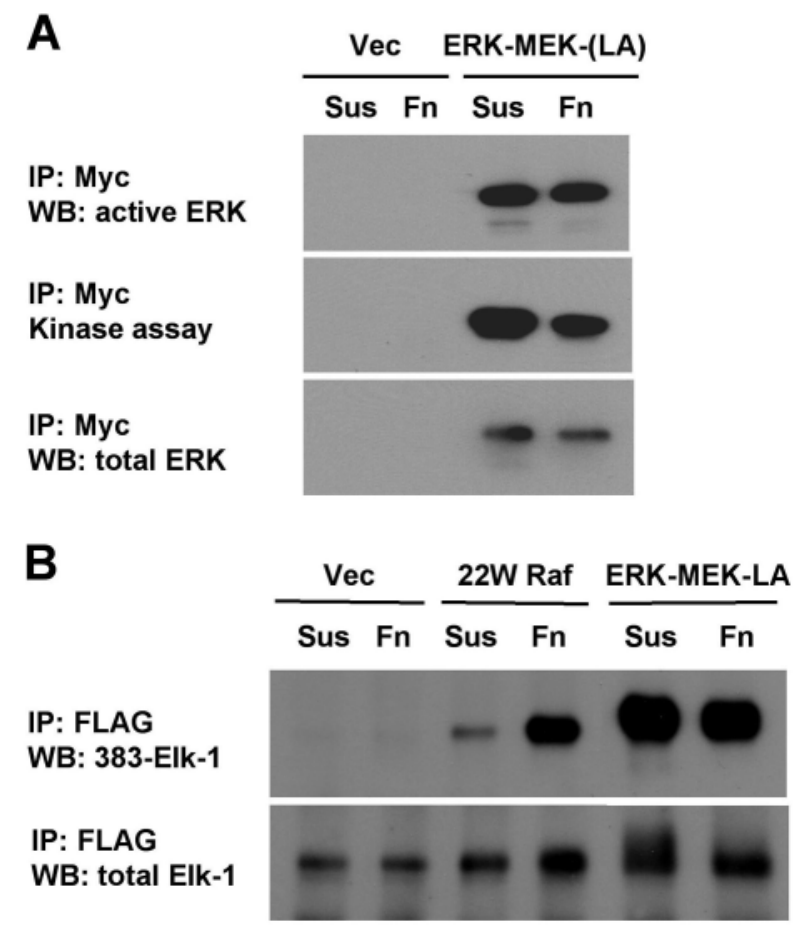

Fig. 7. Expression of ERK2-MEK1-LA phosphorylates Elk-1 efficiently in suspended cells. NIH 3T3 cells were transfected with either pCMV5 (Vec), 22W Raf, or pCMV5-ERK2-MEK1-LA alone (A) or in combination with pCMV5-FLAG-Elk-1 (B). Serum-starved cells were either replated on fibronection (Fn) or maintained in suspension (Sus) for 2 hours in DMEM/BSA. (A) ERK activity was determined by immunoprecipitation with anti-myc antibody followed by western blotting with anti-active ERK antibodies and by in vitro kinase assay using recombinant GST-Elk-1 as the substrate. (B) Elk1 phosphorylation was determined by immunoprecipition from cell lysates with an anti-FLAG antibody and western blotting for levels of Ser383 phosphorylated and total Elk-1. The results shown are representative of three separate experiments.

Recently much attention has been paid to identifying protein-protein interaction domains with the rationale that they will provide the molecular basis for specificity of signaling cascades (Hunter, 2000; Pawson and Nash, 2000). It has been proposed that ERK, JNK and p38 interact with their respective cytoplasmic anchoring proteins through a common docking (CD) domain in the C-terminus of each molecule (Tanoue et al., 2000). The CD domain is characterized by several negatively charged amino acids and is located on the opposite side to the active site. Many of the cytoplasmic anchors that regulate localization of these MAP kinases bind to the $\mathrm{CD}$ domain. For example, ERK is sequestered in the cytoplasm through its association with partners, such as MEK and MAP kinase phosphatase-3 (MKP-3), both of which bind to the CD domain (Camps et al., 1998; Fukuda et al., 1997; Tanoue et al., 2000). MKP1 and 2 also contain CD domain docking motifs and represent likely candidates for nuclear ERK anchoring proteins (Lenormand et al., 1998; Tanoue et al., 2000; Volmat et al., 2001). Furthermore, it has been postulated that nuclear translocation of ERK is dependent upon homodimerization (Khokhlatchev et al., 1998). One attractive possibility from our studies on ERK is that adhesion regulates the release of ERK from its cytoplasmic binding partners and/or homodimerization possibly through an actin-organized scaffold (Aplin et al., 2001; Leinweber et al., 1999). CD regions have also been identified within JNK and p38; however, the identities of the cytoplasmic and nuclear anchors for these MAP kinases are less certain. Nevertheless, adhesion may differentially modulate the manner by which different members of the MAP kinase family interact with cytoplasmic anchor proteins via the $\mathrm{CD}$ domain.

The role of cell adhesion molecules in the regulation of nucleocytoplasmic trafficking of signaling molecules appears to be an emerging concept and warrants further investigation. The ability of cadherins to inhibit translocation of $\beta$-catenin to the nucleus and subsequent activation of LEF/TCF-1mediated transcription events has been well-studied (Gottardi et al., 2001; Orsulic et al., 1999; Sadot et al., 1998). More recently, additional cases whereby cell adhesion receptors regulate the nucleocytoplasmic trafficking of signaling molecules have been found (Bianchi et al., 2000; Hsueh et al., 2000; Zimmermann et al., 2001). In summary, these and our studies highlight the fact that a multitude of connections exist between cell adhesion receptors and key signaling molecules that act as transcriptional regulators. Cell adhesion/actin cytoskeletal regulation of nucleocytoplasmic trafficking may provide a direct channel for communicating information from the extracellular environment to the nucleus.

We gratefully acknowledge the assistance of Mike Fisher with plasmid preparations. We thank Andrew Sharrocks (School of Biological Sciences, University of Manchester, UK), Gary Johnson (University of Colorado Health Sciences Center, Denver), Melanie Cobb (Southwestern Medical Center, University of Texas), and Jiahuai Han (The Scripps Research Institute, La Jolla, CA) for plasmid gifts. This work was supported by National Institutes of Health grants, GM26165 and HL45100, to R.L.J.

\section{References}

Adachi, M., Fukuda, M. and Nishida, E. (1999). Two co-existing mechanisms for nuclear import of MAP kinase: passive diffusion of a monomer and active transport of a dimer. EMBO J. 18, 5347-5358.

Almeida, E. A., Ilic, D., Han, Q., Hauck, C. R., Jin, F., Kawakatsu, H., Schlaepfer, D. D. and Damsky, C. H. (2000). Matrix survival signaling: from fibronectin via focal adhesion kinase to c-Jun NH(2)-terminal kinase. J. Cell Biol. 149, 741-754.

Aplin, A. E. and Juliano, R. L. (1999). Integrin and cytoskeletal regulation of growth factor signaling to the MAP kinase pathway. J. Cell Sci. 112, 695706.

Aplin, A. E., Stewart, S. A., Assoian, R. K. and Juliano, R. L. (2001). Integrin-mediated adhesion regulates ERK nuclear translocation and phosphorylation of Elk-1. J. Cell Biol. 16, 273-282.

Behrens, A., Sibilia, M. and Wagner, E. F. (1999). Amino-terminal phosphorylation of c-Jun regulates stress-induced apoptosis and cellular proliferation. Nat. Genet. 21, 326-329.

Ben-Levy, R., Hooper, S., Wilson, R., Paterson, H. F. and Marshall, C. J. (1998). Nuclear export of the stress-activated protein kinase p38 mediated by its substrate MAPKAP kinase-2. Curr. Biol. 8, 1049-1057.

Bianchi, E., Denti, S., Granata, A., Bossi, G., Geginat, J., Villa, A., Rogge, L. and Pardi, R. (2000). Integrin LFA-1 interacts with the transcriptional co-activator JAB1 to modulate AP-1 activity. Nature 404, 617-621.

Brunet, A. and Pouyssegur, J. (1996). Identification of MAP kinase domains by redirecting stress signals into growth factor responses. Science 272, 16521655.

Brunet, A., Roux, D., Lenormand, P., Dowd, S., Keyse, S. and Pouyssegur, J. (1999). Nuclear translocation of p42/p44 mitogen-activated protein kinase is required for growth factor-induced gene expression and cell cycle entry. EMBO J. 18, 664-674. 
Calderwood, D. A., Shattil, S. J. and Ginsberg, M. H. (2000). Integrins and actin filaments: reciprocal regulation of cell adhesion and signaling. J. Biol. Chem. 275, 22607-22610.

Camps, M., Nichols, A., Gillieron, C., Antonsson, B., Muda, M., Chabert, C., Boschert, U. and Arkinstall, S. (1998). Catalytic activation of the phosphatase MKP-3 by ERK2 mitogen-activated protein kinase. Science 280, 1262-1265.

Cavigelli, M., Dolfi, F., Claret, F. X. and Karin, M. (1995). Induction of cfos expression through JNK-mediated TCF/Elk-1 phosphorylation. EMBO J. 14, 5957-5964.

Chang, L. and Karin, M. (2001). Mammalian MAP kinase signalling cascades. Nature 410, 37-40.

Chen, R. H., Sarnecki, C. and Blenis, J. (1992). Nuclear localization and regulation of erk- and rsk-encoded protein kinases. Mol. Cell. Biol. 12, 915927.

Chow, C. W., Rincon, M., Cavanagh, J., Dickens, M. and Davis, R. J. (1997). Nuclear accumulation of NFAT4 opposed by the JNK signal transduction pathway. Science 278, 1638-1641.

Cobb, M. H. and Goldsmith, E. J. (2000). Dimerization in MAP-kinase signaling. Trends Biochem. Sci. 25, 7-9.

Cyert, M. S. (2001). The regulation of nuclear localization during signal transduction. J. Biol. Chem. 276, 20805-20808.

Danilkovitch, A., Donley, S., Skeel, A. and Leonard, E. J. (2000). Two independent signaling pathways mediate the antiapoptotic action of macrophage-stimulating protein on epithelial cells. Mol. Cell. Biol. 20, 2218-2227.

Davis, R. J. (2000). Signal transduction by the JNK group of MAP kinases. Cell 103, 239-252.

del Pozo, M. A., Price, L. S., Alderson, N. B., Ren, X. D. and Schwartz, M. A. (2000). Adhesion to the extracellular matrix regulates the coupling of the small GTPase Rac to its effector PAK. EMBO J. 19, 2008-2014.

Derijard, B., Raingeaud, J., Barrett, T., Wu, I. H., Han, J., Ulevitch, R. J. and Davis, R. J. (1995). Independent human MAP-kinase signal transduction pathways defined by MEK and MKK isoforms. Science 267, 682-685.

Dickens, M., Rogers, J. S., Cavanagh, J., Raitano, A., Xia, Z., Halpern, J. R., Greenberg, M. E., Sawyers, C. L. and Davis, R. J. (1997). A cytoplasmic inhibitor of the JNK signal transduction pathway. Science 277, 693-696.

Engel, K., Kotlyarov, A. and Gaestel, M. (1998). Leptomycin B-sensitive nuclear export of MAPKAP kinase 2 is regulated by phosphorylation. EMBO J. 15, 3363-3371.

Fanger, G. R., Johnson, N. L. and Johnson, G. L. (1997). MEK kinases are regulated by EGF and selectively interact with Rac/Cdc42. EMBO J. 16, 4961-4972.

Ferrigno, P., Posas, F., Koepp, D., Saito, H. and Silver, P. A. (1998). Regulated nucleo/cytoplasmic exchange of HOG1 MAPK requires the importin beta homologs NMD5 and XPO1. EMBO J. 17, 5606-5614.

Fukuda, M., Gotoh, Y. and Nishida, E. (1997). Interaction of MAP kinase with MAP kinase kinase: its possible role in the control of nucleocytoplasmic transport of MAP kinase. EMBO J. 16, 1901-1908.

Gaits, F. and Russell, P. (1999). Active nucleocytoplasmic shuttling required for function and regulation of stress-activated kinase Spc1/StyI in fission yeast. Mol. Biol. Cell 10, 1395-1407.

Garrington, T. P. and Johnson, G. L. (1999). Organization and regulation of mitogen-activated protein kinase signaling pathways. Curr. Opin. Cell Biol. 11, 211-218.

Gille, H., Strahl, T. and Shaw, P. E. (1995). Activation of ternary complex factor Elk-1 by stress-activated protein kinases. Curr. Biol. 5, 1191-1200.

Gilmore, A. P., Metcalfe, A. D., Romer, L. H. and Streuli, C. H. (2000). Integrin-mediated survival signals regulate the apoptotic function of Bax through its conformation and subcellular localization. J. Cell Biol. 149, 431446.

Gorlich, D. and Kutay, U. (1999). Transport between the cell nucleus and the cytoplasm. Annu. Rev. Cell Dev. Biol. 15, 607-660.

Gottardi, C. J., Wong, E. and Gumbiner, B. M. (2001). E-cadherin suppresses cellular transformation by inhibiting beta-catenin signaling in an adhesion-independent manner. J. Cell Biol. 153, 1049-1060.

Han, J., Lee, J. D., Jiang, Y., Li, Z., Feng, L. and Ulevitch, R. J. (1996). Characterization of the structure and function of a novel MAP kinase kinase (MKK6). J. Biol. Chem. 271, 2886-2891.

Han, J., Wang, X., Jiang, Y., Ulevitch, R. J. and Lin, S. (1997). Identification and characterization of a predominant isoform of human MKK3. FEBS Lett. 403, 19-22.
Hazzalin, C. A., Cano, E., Cuenda, A., Barratt, M. J., Cohen, P. and Mahadevan, L. C. (1996). p38/RK is essential for stress-induced nuclear responses: JNK/SAPKs and c-Jun/ATF-2 phosphorylation are insufficient. Curr. Biol. 6, 1028-1031.

Howe, A. K., Aplin, A. E. and Juliano, R. L. (2002). Anchorage-dependent ERK signaling - mechanisms and consequences. Curr. Opin. Genet. Dev. 12, 30-35.

Hsueh, Y. P., Wang, T. F., Yang, F. C. and Sheng, M. (2000). Nuclear translocation and transcription regulation by the membrane-associated guanylate kinase CASK/LIN-2. Nature 404, 298-302.

Hunter, T. (2000). Signaling - 2000 and beyond. Cell 100, 113-127.

Hynes, R. O. (1992). Integrins: versatility, modulation, and signaling in cell adhesion. Cell 69, 11-25.

Ichijo, H., Nishida, E., Irie, K., ten Dijke, P., Saitoh, M., Moriguchi, T., Takagi, M., Matsumoto, K., Miyazono, K. and Gotoh, Y. (1997). Induction of apoptosis by ASK1, a mammalian MAPKKK that activates SAPK/JNK and p38 signaling pathways. Science 275, 90-94.

Ip, Y. T. and Davis, R. J. (1998). Signal transduction by the c-Jun N-terminal kinase (JNK)-from inflammation to development. Curr. Opin. Cell Biol. 10, 205-219.

Janknecht, R., Ernst, W. H., Pingoud, V. and Nordheim, A. (1993). Activation of ternary complex factor Elk-1 by MAP kinases. EMBO J. 12, 5097-5104.

Kawasaki, H., Moriguchi, T., Matsuda, S., Li, H. Z., Nakamura, S., Shimohama, S., Kimura, J., Gotoh, Y. and Nishida, E. (1996). Rasdependent and Ras-independent activation pathways for the stress-activatedprotein-kinase cascade. Eur. J. Biochem. 241, 315-321.

Khokhlatchev, A. V., Canagarajah, B., Wilsbacher, J., Robinson, M., Atkinson, M., Goldsmith, E. and Cobb, M. H. (1998). Phosphorylation of the MAP kinase ERK2 promotes its homodimerization and nuclear translocation. Cell 93, 605-615.

Kim, K., Nose, K. and Shibanuma, M. (2000). Significance of nuclear relocalization of ERK1/2 in reactivation of c-fos transcription and DNA synthesis in senescent fibroblasts. J. Biol. Chem. 275, 20685-20692.

Leinweber, B. D., Leavis, P. C., Grabarek, Z., Wang, C. L. and Morgan, K. G. (1999). Extracellular regulated kinase (ERK) interaction with actin and the calponin homology $(\mathrm{CH})$ domain of actin-binding proteins. Biochem. J. 344, 117-123.

Lenormand, P., Sardet, C., Pages, G., L'Allemain, G., Brunet, A. and Pouyssegur, J. (1993). Growth factors induce nuclear translocation of MAP kinases (p42mapk and p44mapk) but not of their activator MAP kinase kinase (p45mapkk) in fibroblasts. J. Cell Biol. 122, 1079-1088.

Lenormand, P., Brondello, J. M., Brunet, A. and Pouyssegur, J. (1998). Growth factor-induced p42/p44 MAPK nuclear translocation and retention requires both MAPK activation and neosynthesis of nuclear anchoring proteins. J. Cell Biol. 142, 625-633.

Lewis, J. M., Baskaran, R., Taagepera, S., Schwartz, M. A. and Wang, J. Y. (1996). Integrin regulation of c-Abl tyrosine kinase activity and cytoplasmic-nuclear transport. Proc. Natl. Acad. Sci. USA 93, 15174-15179.

Lin, A., Minden, A., Martinetto, H., Claret, F. X., Lange-Carter, C., Mercurio, F., Johnson, G. L. and Karin, M. (1995). Identification of a dual specificity kinase that activates the Jun kinases and p38-Mpk2. Science 268, 286-290.

Lin, T. H., Aplin, A. E., Shen, Y., Chen, Q., Schaller, M., Romer, L., Aukhil, I. and Juliano, R. L. (1997). Integrin-mediated activation of MAP kinase is independent of FAK: evidence for dual integrin signaling pathways in fibroblasts. J. Cell Biol. 136, 1385-1395.

MacKenna, D. A., Dolfi, F., Vuori, K. and Ruoslahti, E. (1998). Extracellular signal-regulated kinase and c-Jun NH2-terminal kinase activation by mechanical stretch is integrin-dependent and matrix-specific in rat cardiac fibroblasts. J. Clin. Invest. 101, 301-310.

Mainiero, F., Murgia, C., Wary, K. K., Curatola, A. M., Pepe, A., Blumemberg, M., Westwick, J. K., Der, C. J. and Giancotti, F. G. (1997). The coupling of alpha6beta4 integrin to Ras-MAP kinase pathways mediated by Shc controls keratinocyte proliferation. EMBO J. 16, 23652375.

Meier, R., Rouse, J., Cuenda, A., Nebreda, A. R. and Cohen, P. (1996). Cellular stresses and cytokines activate multiple mitogen-activated-protein kinase kinase homologues in PC12 and KB cells. Eur. J. Biochem. 236, 796805 .

Minden, A., Lin, A., Smeal, T., Derijard, B., Cobb, M., Davis, R. and Karin, M. (1994). c-Jun N-terminal phosphorylation correlates with activation of the JNK subgroup but not the ERK subgroup of mitogenactivated protein kinases. Mol. Cell. Biol. 14, 6683-6688. 
Miyamoto, S., Akiyama, S. K. and Yamada, K. M. (1995). Synergistic roles for receptor occupancy and aggregation in integrin transmembrane function. Science 267, 883-885.

Mizukami, Y., Yoshioka, K., Morimoto, S. and Yoshida, K. (1997). A novel mechanism of JNK1 activation. Nuclear translocation and activation of JNK1 during ischemia and reperfusion. J. Biol. Chem. 272, 16657-16662.

Moriguchi, T., Kuroyanagi, N., Yamaguchi, K., Gotoh, Y., Irie, K., Kano, T., Shirakabe, K., Muro, Y., Shibuya, H., Matsumoto, K. et al. (1996). A novel kinase cascade mediated by mitogen-activated protein kinase kinase 6 and MKK3. J. Biol. Chem. 271, 13675-13679.

Oktay, M., Wary, K. K., Dans, M., Birge, R. B. and Giancotti, F. G. (1999). Integrin-mediated activation of focal adhesion kinase is required for signaling to Jun NH2-terminal kinase and progression through the G1 phase of the cell cycle. J. Cell Biol. 145, 1461-1469.

Ono, K. and Han, J. (2000). The p38 signal transduction pathway: activation and function. Cell Signal. 12, 1-13.

Orsulic, S., Huber, O., Aberle, H., Arnold, S. and Kemler, R. (1999). Ecadherin binding prevents beta-catenin nuclear localization and betacatenin/LEF-1-mediated transactivation. J. Cell Sci. 112, 1237-1245.

Pawson, T. and Nash, P. (2000). Protein-protein interactions define specificity in signal transduction. Genes Dev. 14, 1027-1047.

Pedram, A., Razandi, M. and Levin, E. R. (1998). Extracellular signalregulated protein kinase/Jun kinase cross-talk underlies vascular endothelial cell growth factor-induced endothelial cell proliferation. J. Biol. Chem. 273, 26722-26728.

Price, M. A., Cruzalegui, F. H. and Treisman, R. (1996). The p38 and ERK MAP kinase pathways cooperate to activate ternary complex factors and cfos transcription in response to UV light. EMBO J. 15, 6552-6563.

Raingeaud, J., Gupta, S., Rogers, J. S., Dickens, M., Han, J., Ulevitch, R. J. and Davis, R. J. (1995). Pro-inflammatory cytokines and environmental stress cause p38 mitogen-activated protein kinase activation by dual phosphorylation on tyrosine and threonine. J. Biol. Chem. 270, 7420-7426.

Raingeaud, J., Whitmarsh, A. J., Barrett, T., Derijard, B. and Davis, R. J. (1996). MKK3- and MKK6-regulated gene expression is mediated by the p38 mitogen- activated protein kinase signal transduction pathway. Mol. Cell. Biol. 16, 1247-1255.

Read, M. A., Whitley, M. Z., Gupta, S., Pierce, J. W., Best, J., Davis, R. J. and Collins, T. (1997). Tumor necrosis factor alpha-induced E-selectin expression is activated by the nuclear factor-kappa B and c-Jun N-terminal kinase/p38 mitogen-activated protein kinase pathways. J. Biol. Chem. 272, 2753-2761.

Robinson, M. J., Stippec, S. A., Goldsmith, E., White, M. A. and Cobb, M. H. (1998). A constitutively active and nuclear form of the MAP kinase
ERK2 is sufficient for neurite outgrowth and cell transformation. Curr. Biol. 8, 1141-1150.

Sadot, E., Simcha, I., Shtutman, M., Ben-Ze'ev, A. and Geiger, B. (1998). Inhibition of beta-catenin-mediated transactivation by cadherin derivatives. Proc. Natl. Acad. Sci. USA 95, 15339-15344.

Sanchez, I., Hughes, R. T., Mayer, B. J., Yee, K., Woodgett, J. R., Avruch, J., Kyriakis, J. M. and Zon, L. I. (1994). Role of SAPK/ERK kinase-1 in the stress-activated pathway regulating transcription factor c-Jun. Nature 372, 794-798.

Schwartz, M. A. and Baron, V. (1999). Interactions between mitogenic stimuli, or, a thousand and one connections. Curr. Opin. Cell Biol. 11, 197202.

Short, S. M., Talbott, G. A. and Juliano, R. L. (1998). Integrin-mediated signaling events in human endothelial cells. Mol. Biol. Cell 9, 1969-1980.

Stein, B., Brady, H., Yang, M. X., Young, D. B. and Barbosa, M. S. (1996). Cloning and characterization of MEK6, a novel member of the mitogen-activated protein kinase kinase cascade. J. Biol. Chem. 10, 11427 11433.

Tanoue, T., Adachi, M., Moriguchi, T. and Nishida, E. (2000). A conserved docking motif in MAP kinases common to substrates, activators and regulators. Nat. Cell Biol. 2, 110-116.

Tournier, C., Whitmarsh, A. J., Cavanagh, J., Barrett, T. and Davis, R. J. (1997). Mitogen-activated protein kinase kinase 7 is an activator of the cJun NH2-terminal kinase. Proc. Natl. Acad. Sci. USA 94, 7337-7342.

Volmat, V., Camps, M., Arkinstall, S., Pouyssegur, J. and Lenormand, P. (2001). The nucleus, a site for signal termination by sequestration and inactivation of p42/p44 MAP kinases. J. Cell Sci. 114, 3433-3443.

Wang, X. Z. and Ron, D. (1996). Stress-induced phosphorylation and activation of the transcription factor CHOP (GADD153) by p38 MAP Kinase. Science 272, 1347-1349.

Whitmarsh, A. J., Shore, P., Sharrocks, A. D. and Davis, R. J. (1995). Integration of MAP kinase signal transduction pathways at the serum response element. Science 269, 403-407.

Woodring, P. J., Hunter, T. and Wang, J. Y. (2001). Inhibition of c-Abl tyrosine kinase by filamentous-actin. J. Biol. Chem. 276, 27104-27110.

Yang, S. H., Whitmarsh, A. J., Davis, R. J. and Sharrocks, A. D. (1998). Differential targeting of MAP kinases to the ETS-domain transcription factor Elk-1. EMBO J. 17, 1740-1749.

Zimmermann, P., Tomatis, D., Rosas, M., Grootjans, J., Leenaerts, I., Degeest, G., Reekmans, G., Coomans, C. and David, G. (2001). Characterization of syntenin, a syndecan-binding PDZ protein, as a component of cell adhesion sites and microfilaments. Mol. Biol. Cell 12, 339-350. 